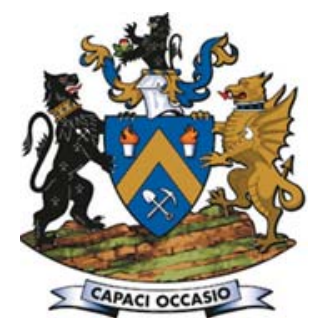

\title{
Effect of niobium on the solidification structure and properties of hypoeutectic high-chromium white cast irons
}

\author{
by M.E. Maja*†, M.G. Maruma*, L.A. Mampuru* and \\ S.J. Moema*
}

\section{Synopsis}

The most commonly used high-chromium white cast iron (HCWCI) is the hypoeutectic white cast iron that contains $2-3.5 \mathrm{wt} . \% \mathrm{C}$ and $10-30 \% \mathrm{Cr}$. This type of material relies on hard, brittle $M_{7} C_{3}$ carbides to impart good wear resistance. Due to its good wear resistance, this material has found application in the mining industry and cement industry. However, it has low fracture strength and this challenge led to research aimed at refining the microstructure. This was done by the addition of niobium in the range between 0.1 and $0.6 \mathrm{wt} . \%$. In the as-cast condition, the addition of niobium was found to increase the fracture strength due to the finer eutectic microstructure. The hardness was also found to have increased slightly compared to the reference alloy with no niobium additions. Low fracture strength after heat treatment was observed in the Nb-added HCWCI, which is believed to have been caused by the precipitation of secondary carbides and the transformation of the matrix from austenite to martensitic.

\section{Keywords}

HCWCI, niobium, grain refinement, fracture strength.

\section{Introduction}

For the past few years Mintek has been involved in a project in which a number of alloys have been identified for grinding media applications. The high-chromium white cast iron (HCWCI) alloys were among the alloys researched for this application. The knowledge acquired from the grinding ball media research has now been extended to mill liners, which have traditionally been made of manganese-, chromium- and chrome-molybdenum steels. The replacement of worn mill liners costs the mining industry a significant amount of money and this has led to a need for continuous research to prolong the life of the liners. During milling operations, liner wear has an adverse effect on the capacity of the mill, the energy efficiency and milling efficiency and finally leads to relining, to replace worn liners.

The mill efficiency depends on the charge motion, which in turn is largely influenced by the liner profiles and performance. The choice of a liner requires a holistic approach that examines the compatibility with the mill conditions, the mechanical performance and the cost-effectiveness. The operating conditions in a fine grinding mill require that the liner should be made of highly wear- resistant material with some fracture strength such as (HCWCI).

HCWCI contains a minimum of $2 \% \mathrm{C}$ with a chromium content ranging from $15 \%$ to $35 \%$. The term 'white cast iron' refers to the appearance of a white fractured surface in the material after damage, due to the presence of white cementite. This material has been proven to be effective for applications in aggressive environments where wear and erosion resistance are required. The high wear resistance of $\mathrm{HCWCI}$ is attributed to the microstructural constituents such as hard primary and/or eutectic carbides of $\mathrm{M}_{7} \mathrm{C}_{3}$ (where $\mathrm{M}$ is iron, chromium and other strong carbide formers) and a relatively ductile ferrous matrix (Bedolla-Jacuinde et al., 2005, 2007; Adler and Dogan, 1999; Dogan, Hawk and Laird, 1997; Stevenson and Hutchings, 1995; Radzikowska, 2004). Austenitizing at a temperature above $1100^{\circ} \mathrm{C}$ leads to the precipitation $\mathrm{M}_{7} \mathrm{C}_{3}$ carbides while below $1100^{\circ} \mathrm{C}$ the precipitation of both $\mathrm{M}_{7} \mathrm{C}_{3}$ and $\mathrm{M}_{23} \mathrm{C}_{6}$ carbides, which are rich in alloying elements, occurs (Kootsookos and Gates, 2008). The precipitation of secondary carbides lowers the alloy content in the dendritic austenite and thus raises the martensite start temperature, hence the formation of martensite upon cooling (Cetinkaya, 2006).

The hardness of $\mathrm{M}_{7} \mathrm{C}_{3}$ is in the range of 1200 HV (Stevenson and Hutchings, 1995), which may vary with the composition and the ferrous matrix binds the hard $\mathrm{M}_{7} \mathrm{C}_{3}$ carbides and provides the material with certain fracture strength that is vital for handling high impact forces (Bedolla-Jacuinde et al., 2005;

* Advanced Materials Division, Mintek Randburg, Johannesburg, South Africa.

+ Tshwane University of Technology, Pretoria South Africa.

(C) The Southern African Institute of Mining and Metallurgy, 2016. ISSN 2225-6253. This paper was first presented at the AMI Ferrous and Base Metals Development Network Conference 2016 19-21 October 2016, Southern Sun Elangeni Maharani, KwaZulu-Natal, South Africa. 


\section{Effect of niobium on the solidification structure and properties of hypoeutectic}

Cetinkaya, 2006; Lewellyn et al., 2004). Through appropriate heat treatment and alloying, different structures of the matrix can be formed. Pearlite, martensite and austenite are among the typical microstructures of the matrix (Radzikowska, 2004; Cetinkaya, 2006; Lewellyn et al., 2004; Correa et al., 2007; Thorpe and Chicco, 1985; Dolman, 2005). HCWCIs thus typically have high strength and hardness.

However, HCWCIs have low fracture strength. The objective of this project is to improve the life and mechanical properties of the current HCWCI alloys through grain refinement. Grain refinement is the only strengthening method that also improves the fracture strength of iron. Many researchers (Zhang et al., 2014; Zhi et al., 2008a, 2008b) have attempted to improve the mechanical properties of HCWCI through grain refinement, especially in hypereutectic HCWCl. However, their work focused more on improving the wear resistance by increasing the hardness. This work focuses more on improving the fracture strength of the materials by the addition of niobium as a grain refiner. Increasing the fracture strength of HCWCI will open doors for other application outside of the mining industry.

\section{Experimental procedure}

\section{Casting of alloys}

Three HCWCI alloys were melted in a medium-frequency induction furnace with a capacity of about $150 \mathrm{~kg}$. Charge material was prepared to give the targeted chemistry as shown in Table I.

The test materials produced for this project consisted of $\mathrm{HCWCI}$ in the form of $50 \mathrm{~mm} \times 100 \mathrm{~mm} \times 500 \mathrm{~mm}$ rectangular flat test bars (thickness $\times$ width $\times$ length) as shown in Figure 1. The alloys were examined for surface defects before proceeding with testing. Cast iron mould boxes (0.5 m length, $0.38 \mathrm{~m}$ width and $0.14 \mathrm{~m}$ depth) were used to

\section{Table I}

\section{Actual chemical composition of tested alloys}

\begin{tabular}{|l|c|}
\hline Alloy & Composition \\
\hline Alloy 1 & ASTM A 532 Class III \\
Alloy 2 & ASTM A 532 Class III + 0.1-0.4Nb \\
Alloy 3 & ASTM A 532 Class III+ $0.4-0.6 \mathrm{Nb}$ \\
\hline
\end{tabular}

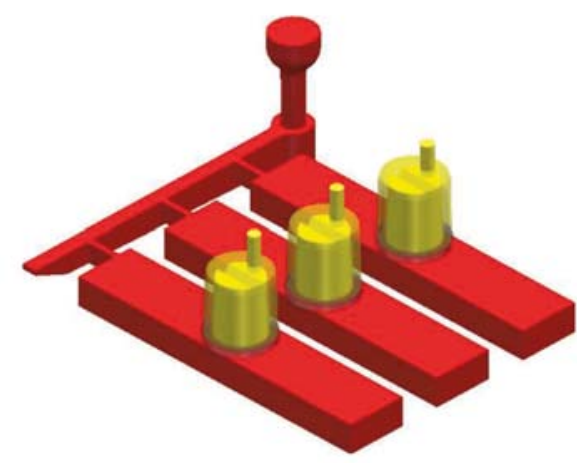

Figure 1-Pattern that was used to produce the alloys accommodate both the drag (bottom) and cope (top) parts of the pattern.

\section{Heat treatment}

The alloys were austenitized at $875^{\circ} \mathrm{C}$ for 3 hours and force air-quenched. Force air-quenching was chosen for an increased cooling rate to avoid the formation of a pearlitic microstructure. The samples were then tempered at $450^{\circ} \mathrm{C}$ for 3 hours then air-cooled to room temperature. This was employed to transform all the retained austenite.

\section{Microstructural analysis}

Specimens were removed from the heat-treated samples, polished and etched with Murakami and 3\% nital. The microstructural analysis was carried out using an Olympus PGM optical microscope equipped with Analysis Image software and by scanning electron microscopy.

\section{Hardness}

Brinell hardness measurements were performed through the cross-sections of the as-cast and heat-treated test samples, using a load of $750 \mathrm{~kg}$. The measurements were taken from the surface to the centre of the rectangular test pieces to evaluate whether there were any hardness changes within the test sample.

\section{Bending tests}

Bending tests are intended for brittle materials when the scope of test is to determine the strength of material. Specimens with dimensions of $50 \times 100 \times 500 \mathrm{~mm}$ were used. The cast blocks were placed in the specially designed mandrel and the load applied to break them without any preparation to the samples (i.e. machining). The specimen is placed on two supports that are $300 \mathrm{~mm}$ apart $(L)$ and the force applied in the exact middle of the two supports $(L / 2)$. To determine the bending strength $Q_{\max }$, the beam must be so proportioned that it will not fail in shear or by lateral deflection before reaching its ultimate flexural strength. Hence, for a rectangular part in a three-point bending test, the bending strength is the highest stress at the moment of rupture. Usually, long specimens with higher length to depth ratio $(L / h>10)$ are recommended.

\section{Results and discussion}

\section{Microstructural analysis}

\section{As-cast alloys}

The microstructures of the as-cast alloys, depicted in Figure 2, consist of primary austenite dendrites surrounded by a eutectic mixture of carbide particles and austenite. It can been seen from Figure 2 that the $\mathrm{M}_{7} \mathrm{C}_{3}$ carbides are rod- and needle-like in morphology and that the stress concentration at the tips of the needle-type carbides will play a major role when the material is subjected to impact loading. Addition of niobium to HCWCI has changed the morphology of the rodshaped $\mathrm{M}_{7} \mathrm{C}_{3}$ to isotropic. This change in carbide morphology plays a critical role determining the fracture strength of the HCWCl.

Etching with $3 \%$ nital revealed the presence of a thin dark layer surrounding the eutectic carbides. This layer was found 


\section{Effect of niobium on the solidification structure and properties of hypoeutectic}

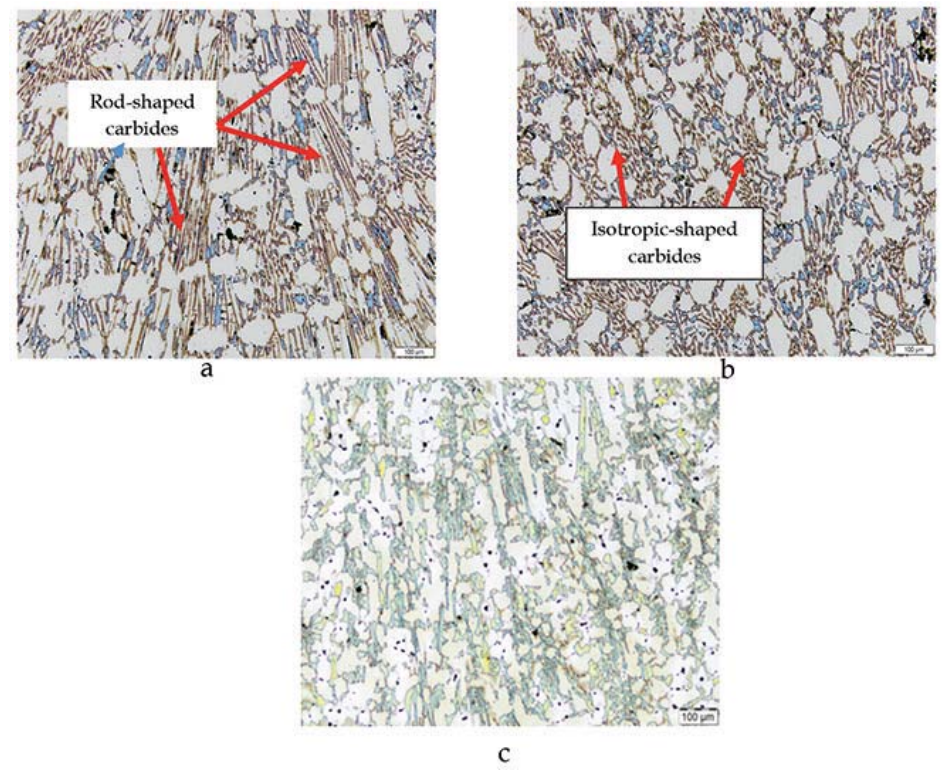

Figure 2-Effect of niobium on the microstructure of $\mathrm{HCWCl}$ (a) $0 \% \mathrm{Nb}$, (b) $0.1-0.4 \%$ and $\mathrm{Nb}$ (c) $(0.4-0.6 \% \mathrm{Nb})$

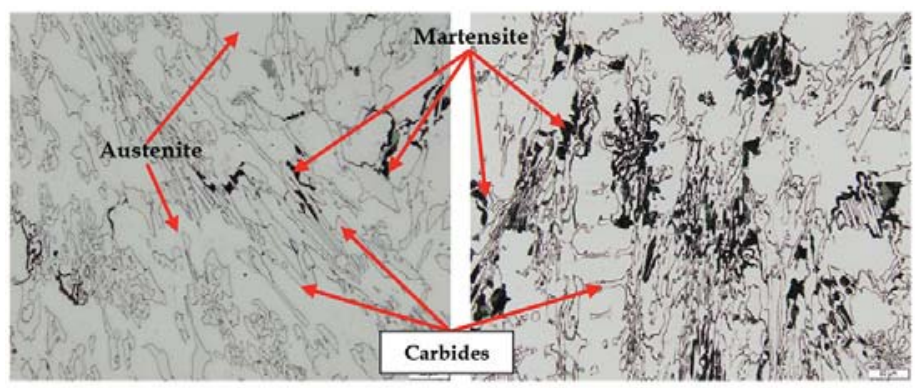

Figure 3-Microstructures of $\mathrm{HCWCl}$ with $0.1-0.4 \%$ and $0.4-0.6 \% \mathrm{Nb}$ showing the presence of martensite at the carbide interface

to be martensite (Figure 3). According to the literature (Zum Gahr and Eldis, 1980; Matsubara et al., 2001; Turenne et al., 1989; Tabrette and Sare, 1998, 1997, 2000; Tabrette et al., 1996) the formation of the eutectic carbides in contact with the primary austenitic phase leads to excessive consumption of carbon and chromium in the interfacial region, depleting these elements in the interface and increasing the $M_{s}$ temperature. As a result, martensite forms at the periphery of the primary carbide particles.

The role of the $\mathrm{Nb}$ in grain refinement can be explained as follows. The formation of the first precipitated $\mathrm{NbC}$ reduces the carbon available to form primary $\mathrm{M}_{7} \mathrm{C}_{3}$ carbides and as a result the volume fraction and the size of the primary $M_{7} C_{3}$ carbides decreases (Zhi et al., 2008b). The concentration of $\mathrm{Nb}$ in the matrix and $\mathrm{M}_{7} \mathrm{C}_{3}$ is very low as this element tends to partition into $\mathrm{NbC}$ in the Fe-Cr-Cr (Zhi et al., 2008b; Hannes and Gates, 1997; Coelho et al., 2003; Baik and Loper, 1998). This results in niobium enrichment at the grain boundaries of the carbides during solidification until $\mathrm{NbC}$ precipitates due to solubility of $\mathrm{Nb}$ at the grain boundaries being exceeded. The precipitated $\mathrm{NbC}$ impedes the preferential directional growth of the $\mathrm{M}_{7} \mathrm{C}_{3}$ carbides and result in finer, isotropic carbides (Fiset et al., 1993; Zhi et al., 2008b).

\section{Heat-treated alloys}

Figure 4 shows the microstructural analysis of the HCWCI after heat treatment. It is evident that the morphology of the microstructure has changed significantly from the as-cast condition. After heat treatment the microstructures reveals the presence of primary and eutectic carbides in a martensitic matrix. Precipitation of secondary carbides during austenitising resulted in the depletion of carbon in the austenite and during quenching the austenite partially transformed to martensite (see Figure 5). Addition of niobium resulted in grain refinement of the $\mathrm{HCWCI}$.

The presence of $\mathrm{NbC}$ was also evident from SEM-EDX mapping as shown by the dark spots in Figures 6 and 7 . Niobium is a strong carbide-forming element and it has been found that $\mathrm{NbC}$ particles are formed before the precipitation of primary carbides when niobium is added into the melts (Fiset et al., 1993).

\section{Effect of niobium on hardness}

The effect of niobium on the hardness of HCWCI is also given in Table II. It can be seen that the as-cast hardness firstly increases with the addition of $\mathrm{Nb}$ and then decreases with a further increase in niobium. 


\section{Effect of niobium on the solidification structure and properties of hypoeutectic}
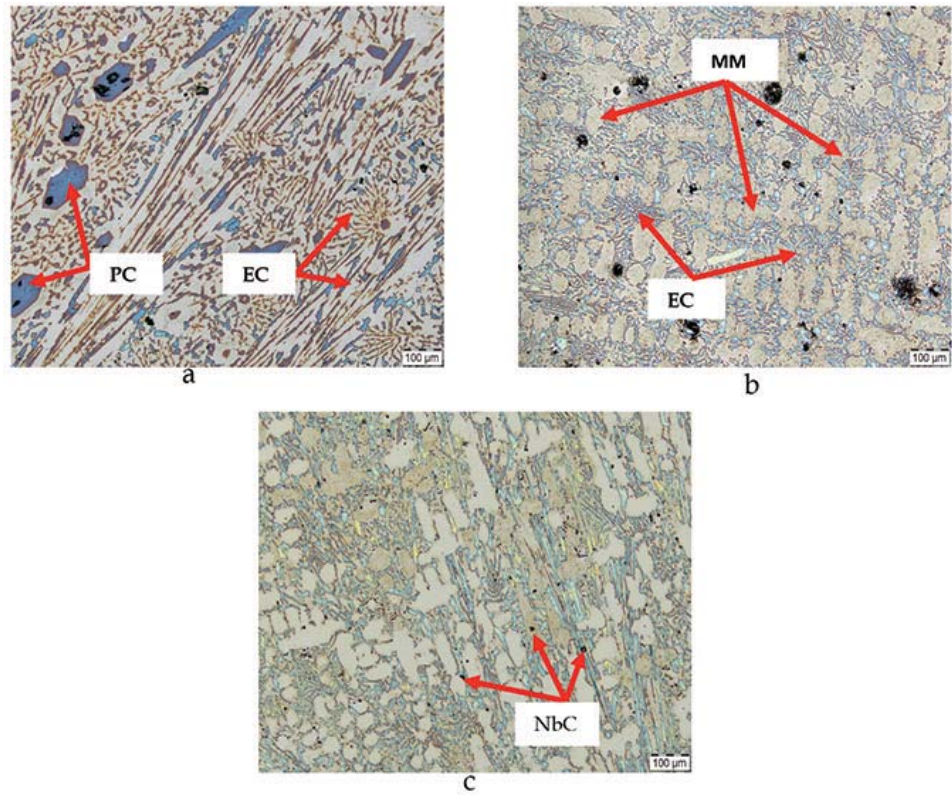

Figure 4-Effect of niobium on the microstructure of $\mathrm{HCWCl}$ (a) $0 \% \mathrm{Nb}$, (b) $0.1-0.4 \% \mathrm{Nb}$ and (c) $(0.4-0.6 \% \mathrm{Nb})$. PC=primary carbides, EC=eutectic carbides, $M M=$ martensitic matrix

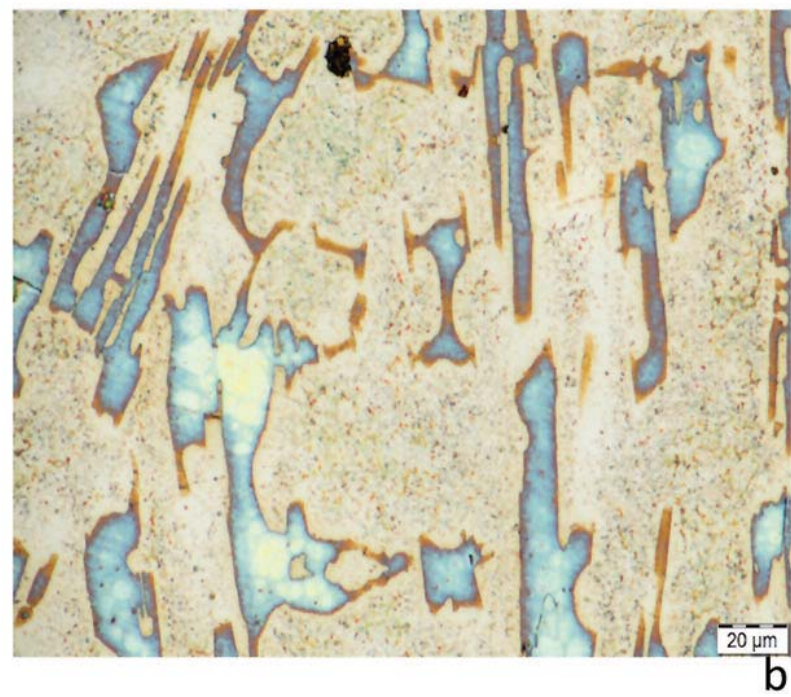

Figure 5-High-magnification microstructure of $\mathrm{HCWCl}$ with $0.1-0.4 \% \mathrm{Nb}$ showing the presence of secondary carbides (dark spots within the matrix)

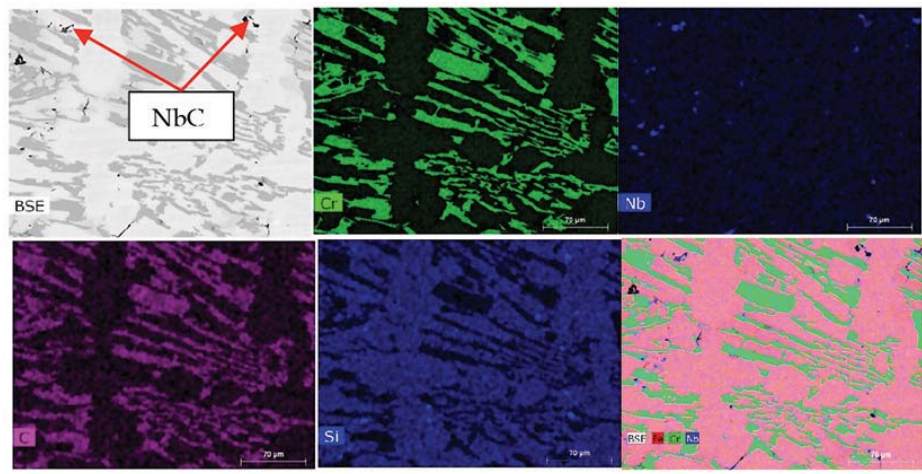

Figure 6-SEM-EDX mapping of the as-cast $\mathrm{HCWCl}$ with addition of $0.1-0.4 \% \mathrm{Nb}$ 


\section{Effect of niobium on the solidification structure and properties of hypoeutectic}

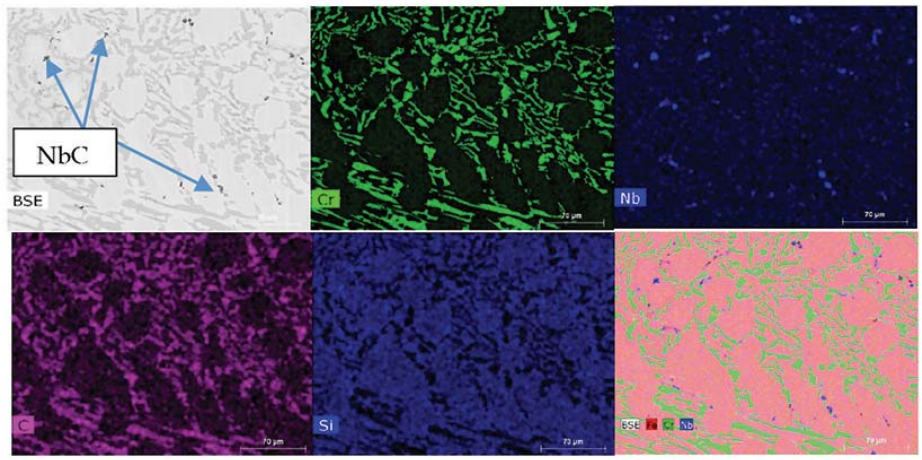

Figure 7-EDS mapping of the as-cast $\mathrm{HCWCl}$ with addition of $0.4-0.6 \% \mathrm{Nb}$

Table II

The effect of niobium on the hardness of $\mathrm{HCWCl}$

\begin{tabular}{|l|c|}
\hline Alloy & Brinell hardness average (BHN) \\
\hline Reference & 432 \\
$0.1-0.4 \% \mathrm{Nb}$ alloy & 485 \\
$0.4-0.6 \% \mathrm{Nb}$ alloy & 438 \\
Reference (HT) & 457 \\
$0.1-0.4 \% \mathrm{Nb}$ alloy (HT) & 354 \\
$0.4-0.6 \% \mathrm{Nb}$ alloy (HT) & 426 \\
\hline
\end{tabular}

The decrease in hardness can be attributed to a decrease in the carbide volume fraction. The formation of the first precipitated carbides consumed carbon in the alloy, so the total volume fracture of $\mathrm{M}_{7} \mathrm{C}_{3}$ was reduced. The relationship between total carbide volume fraction and carbon content (weight fraction) is described as follows (Zhou and $\mathrm{Su}, 1986$, as quoted in Matsubara et al., 2001):

$$
V_{\text {total }}=12.33 \mathrm{C}+0.55 \mathrm{Cr}-15.2
$$

Decreasing carbon and chromium lead to a decrease in the total volume fraction of carbides and hence to a decrease in bulk hardness.

\section{Effect of niobium on fracture strength}

The effect of niobium content on the maximum stress required to break the HCWCI is indicated in Table III. It can be seen from the results that niobium has a more positive effect on the fracture strength than on the hardness. It should be mentioned that the impact strength does not depend only on the matrix but also on the volume fraction, distribution, morphology and size of the carbides.

The stress concentration factor plays a bigger role when the material is exposed to impact forces. The micro-cracks of carbides propagate quickly along the direction of minimum resistance. Rod- and needle-like carbides provide an environment for high stress concentration and an easy path for crack propagation, hence they have low fracture strength. Increasing the niobium content led to a finer eutectic microstructure, which was beneficial to the mechanical behaviour of the alloy. Finer, isotropic carbides weaken the stress concentration factor compared to rod-and needle-like carbides (Ma et al., 2013). This will lead to a decrease in the crack propagation rate and when the alloy is subjected to impact, the stress on the carbides can be rapidly transferred to the soft austenite.

As-cast specimens show better fracture strength compared to the heat-treated samples. This can be attributed to the austenite matrix acting as a cushion/arrester of crack propagation by preventing brittle cracks from propagating directly from one carbide grain to another (Ma et al., 2013). Low fracture strength after heat treatment can also be due to the precipitation of secondary carbides and the transformation of the matrix from austenite to martensite. However, on the other hand the martensitic matrix is also recommended for greater hardness and better wear properties at the expense of fracture strength.

\section{Conclusions}

The aim of the project was to improve the mechanical properties of the current high-chromium white cast iron (HCWCI) mill liner material by applying grain refinement. The addition of niobium was found to change the morphology of the eutectic carbides from a plate- and rod-like shape to an isotropic shape. The change in morphology was due the precipitation of niobium carbides $(\mathrm{NbC})$ at the grain boundaries, which impedes the directional growth of the $\mathrm{M}_{7} \mathrm{C}_{3}$ carbides and result in finer, isotropic carbides. Initial addition of niobium led to an increase in hardness and further increase in niobium lead to decrease in hardness of the HCWCI. This trend was attributed to the decrease in carbon content available to form chromium carbides, due to formation of $\mathrm{NbC}$.

Table III

The effect of niobium on the fracture strength of $\mathrm{HCWCI}$

\begin{tabular}{|l|c|c|}
\hline Alloy & Fracture load (N) & Stress $\left(\boldsymbol{Q}_{\text {max }}\right)$ MPa \\
\hline Reference & 184400 & 332 \\
$0.1-0.4 \% \mathrm{Nb}$ alloy & 314450 & 566 \\
$0.4-0.6 \% \mathrm{Nb}$ alloy & 425400 & 767 \\
Reference (HT) & 223500 & 402 \\
$0.1-0.4 \% \mathrm{Nb}$ alloy (HT) & 201200 & 362 \\
$0.4-0.6 \% \mathrm{Nb}$ alloy (HT) & 372650 & 671 \\
\hline
\end{tabular}




\section{Effect of niobium on the solidification structure and properties of hypoeutectic}

The addition of $\mathrm{Nb}$ led to a significant improvement in the fracture strength of both the as-cast and heat-treated alloys. This increase in fracture strength was due to the finer eutectic microstructure. There was a general decrease in the fracture strength after heat treatment, which is attributed to the precipitation of secondary carbides and the transformation of the matrix from soft austenite in as-cast condition to hard and brittle martensite after heat treatment. Austenite has a higher intrinsic fracture strength compared to martensite, but strain-induced martensite from impact forces may further enhance the fracture strength.

\section{Future work}

Industrial liners will be produced using the optimized chemistry. This will be done to validate the laboratory results and for ease of comparison with what is currently in the market.

\section{Acknowledgements}

The authors thank Mintek for financial support and for permission to publish this article.

\section{References}

Adler, T.A. and Dogan, O.N. 1999. Erosive wear and impact damage of highchromium white cast irons. Wear, vol. 229. pp. 174-180.

BAIK, H.K. and LoPER, C.R. 1998. The influence of niobium on the solidification structure of Fe-C-Cr alloys. American Foundry Society Transactions, vol. 96. pp. $405-412$

Bedolla-Jacuinde, A., Correa, R.I. MejÍAA, I., QuezadaA, J.G. and Rainforth, W.M. 2007. The effect of titanium on the wear behaviour of a $16 \% \mathrm{Cr}$ white cast iron under pure sliding. Wear, vol. 263. pp. 808-820.

Bedolla-Jacuinde, A., Correa, R., Quezada, J.G. and Maldonado, C. 2005. Effect of titanium on the as-cast microstructure of a $16 \%$ chromium white iron. Materials Science and Engineering A, vol. 398. pp. 297-308.

Cetinkaya, C. 2006. An investigation of the wear behaviours of white cast irons under different compositions. Materials and Design, vol. 27. pp. 437-445.

Coelho, G.C., Golczewski, J.A. and FischmeISTER, H.F. 2003. Thermodynamic calculations for $\mathrm{Nb}$-containing high-speed steels and white-cast-iron alloys. Metallurgical and Materials Transaction A, vol. 34. pp. 1748-1758.

Correa, E.O., Guedes de Alcântara, N., Tecco, D. and Kumar, R.V. 2007. The relationship between the microstructure and abrasive resistance of a hardfacing alloy in the $\mathrm{Fe}-\mathrm{Cr}-\mathrm{C}-\mathrm{Nb}-\mathrm{V}$ system. Metallurgical and Materials Transactions A, vol. 38. pp. 1671-1680.

Dogan, O.N., HAWK, J.A. and LAIRD, G. 1997. Solidification structure and abrasion resistance of high chromium white irons. Metallurgical and Materials Transactions A, vol. 28. pp. 1315-1328.

DoLman, K.F. 2005. Metallurgy of white cast irons: effect of alloying elements and heat treatment. Proceedings of the 36th Australian Foundry Institute National Conference, Sydney.

Fiset, M., PeEv, K. and Radulovic, M. 1993. The influence of niobium on fracture toughness and abrasion resistance in high-chromium white cast irons. Materials Science Letters, vol. 12. pp. 615-617.
HANNES, S.K. and GATES, J.D. 1997. A transformation toughening white cast iron. Journal of Materials Science, vol. 32. pp. 1249-1259.

Kоотsоoкоs, A. and Gates, J.D. 2008. The role of secondary carbide precipitation on the fracture toughness of a reduced carbon white iron. Materials Science and Engineering A, vol. 490. pp. 313-318.

LLEWELLYN, R.J., YICK, S.K. and DoLman, K. 2004. Scouring erosion resistance of metallic materials used in slurry pump service. Wear, 256. pp. 592-599.

MA, Y., LI, X., LIU, Y. and DANG, X. 2013. Microstructure and properties of Ti$\mathrm{Nb}-\mathrm{V}-\mathrm{Mo}$-alloyed high chromium cast iron. Bulletin of Materials Science, vol. 36 , no. 5. pp. 839-844

Matsubara, Y., Sasaguri, N., Shimizu, K., Yu, S. and Yu, K. 2001. Solidification and abrasion wear of white cast irons alloyed with $20 \%$ carbide forming elements. Wear, vol. 250. pp. 502-510.

RADZiкоWSKA, J.M. 2004. Metallography and microstructures of cast iron. ASM Handbook: Metallography and Microstructures. ASM International, Materials Park, Ohio. pp. 565-587.

Stevenson, A.N.J. and Hutchings, I.M. 1995. Wear of hardfacing while cast irons by solid particle erosion. Wear, vol. 186. pp. 150-158.

TABRETT, C.P. and SARE, I.R. 1997. The effect of heat treatment on the abrasion resistance of alloy white irons. Wear, vol. 203-204. pp. 206-219.

TABRETT, C.P. and SARE, I.R. 1998. Effect of high temperature and sub-ambient treatments on the matrix structure and abrasion resistance of a high chromium white iron, Scripta Materialia, vol. 38, no. 12. pp. 1747-1753.

TABRETT, C.P. and SARE, I.R. 2000. Fracture toughness of high chromium white irons: influence of cast structure. Journal of Materials Science, vol. 35 pp. 2069-2077.

TABRETT, C.P., SARE, R. and GHOMASHCHI, M.R. 1996. Microstructure-property relationships in high chromium white iron alloys. International Materials Reviews, vol. 41, no. 2. pp. 52-89.

Thorpe, W.R. and Chicco, B. 1985. The Fe-rich corner of the metastable C-Cr-Fe liquidus surface. Metallurgical Transactions A, vol. 16. pp. 1541-1549.

TuRenne, S., LAvalléE, F. and Masounave, J. 1989. Matrix microstructure effect in the abrasion resistance of high chromium white cast iron. Journal of Materials Science, vol. 24. pp. 3021-3028.

Zhang, Z., YAng, C., ZHAng, P. and LI, W. 2014. Microstructure and wear resistance of high chromium cast iron containing niobium. China Foundry, vol. 11, no. 3. pp. 179-184.

ZHI, X., XING, J., Fu, H. and GAO, Y. 2008a. Effect of titanium on the as-cast microstructure of hypereutectic high chromium cast iron. Materials Characterisation, vol. 58. pp. 1221-1226.

ZHI, X., XING, J., Fu, H. and XIAO, B. 2008b. Effect of niobium on the as-cast microstructure of hypereutectic high chromium cast iron. Materials Letters, vol. 62. pp. 857-860.

ZHou, Q. and Su, J. 1986. Chromium family of wear resistant cast iron. Xi'an Jiaotong University Press. pp. 111-112. [In Chinese].

ZuM GAHR K.-H and ELDIS, G.T. 1980. Abrasive wear of white cast irons, Wear, vol. 64. pp. $175-194$. 